\title{
Comparison between Analytical Calculus and FEM for a Mechanical Press Bed
}

\author{
Cătălin Iancu* \\ Engineering Faculty, University “Constantin Brâncuşi” of Târgu-Jiu, Romania \\ *Corresponding author: ciancu@utgjiu.ro
}

Received December 29, 2012; Revised January 16, 2013; Accepted February 26, 2013

\begin{abstract}
In the first part of this paper is presented a method for calculating stress of press bed, based on expansion of classic methodology, using reduced frame, determined by the points of application of force and the gravity center line, thus determining sectional geometry and maximum stress. Calculus is extended considering cross sections of the frame, from $15^{\circ}$ to $15^{\circ}$, providing more information on both maximum values and the distribution of these tensions. Values obtained confirm the assumption that using the simplified structure is obtained generally large, the calculation usually used for verification. By this method one can get stresses in different sections, not only the maximum value. For a complete stress value and their distribution require a more complex calculation, furthermore allowing any dimensional optimization, such as FEM. Second, is presented a step-by-step method for modeling the frame of mechanical press studied, using Pro/Engineer, in order to perform consequent static or dynamic analysis based on FEM, using COSMOS/M. So are presented the stages of defining the mesh, the environment bonds, the loads, and finally performing analysis and result interpretation. According to FEA results a continuous distribution of displacements and stresses that validate the model. At the end are presented considerations and comparison between the results of analytical method and FEM, regarding stress values and their distribution.
\end{abstract}

Keywords: CAD/FEA software, complex structures, mechanical press, modeling, FEM, stress distribution

\section{Introduction}

The press frame is a basic element of the press, aiming to support all of the machine kinematics and force transmission from the press to the work-piece. In this paper is considered the frame for a crank press, one of the most common types of such machines. Properly working characteristics and for functional reasons, as specified in OSHA 1910.217 [1], crank mechanical presses frames are made in two models: half frames (open) and complete frames (closed).

Open frames are distinguished by the shape of the normal section made through the column, at table level, and it can be assembled mono-block design or assembled construction.

The column can have one or two uprights, second version allowing through the opening between columns to increase the workspace of the die, and easier parts and waste disposal. Columns or pillars are secured by means of ribs and some braces. Common variants of the cross sections can be mentioned: closed contour, half contour, open contours or cross-section profile of T. Frames after a closed contour presses are used for fixed and the semiclosed or open contours for both fixed press and for the folding ones.

As specified in the Machine-tools, typification rules [2], the materials used in performing frames are cast iron and steel castings Fc 250...Fc 350 (Ft 25D...Ft 35D according to NF-A 35-501-77) or OT (cast steel) class for cast frames, and steel type OL 37 , OL $42.2 \mathrm{k}$, OL $44.2 \mathrm{k}$ and OL 52.2k (E 24-2, E 26-2, E 30-2 and E 36-2 according to NF-A 35-501-77) for welded frames of plates.

The selection of construction materials is subject, however, largely by pressing force. Thus, for forces ranging from $63 \mathrm{kN}$...1600 $\mathrm{kN}$ can be used open frames with two columns (pillars) reclining or tilt-bed, or open frames with two columns fixed and folding table. Open section frames with closed contour section are used in the range of $63 \mathrm{kN} . .1600 \mathrm{kN}$, but can be used even for higher nominal force. In the same limits size, closed frames are approx. $15 \%$ more rigid than open frameworks, the decisive factor in choosing the technology and construction of the frame being technical-economic considerations.

\section{Crank Mechanical Press Bed Calculus}

For presses with capacities up to a nominal force of $5000 \mathrm{kN}$, such as universal or blanking presses, eccentric or crank drive is still the most effective drive system [3]. Mechanical presses crank bearing pedestal calculation is based on the determination of stresses and strains that occur under full load, for the nominal pressing force.

In terms of static calculation performed, types of frames for these presses are divided into three general categories [4]:

1. Frame with a single upright, considered a straight beam eccentric loaded, crank shaft being eccentric type end, oriented transversely (perpendicular to the machine). 
2. Frame with a single upright, double, tilt usually, regarded as a curved beam eccentric loaded, crank shaft being oriented longitudinally (parallel to the machine).

3. Frame with two uprights, loaded symmetrically, for closed presses, crank shaft being placed longitudinally or transversely.

As Tabără et al. shown in [5], and Tschaetsch in [6] the calculation considers a flat charging, concentrated forces acting in the plane of symmetry of the bearing pedestal.

Following will be treated half frame bearing pedestal (open), crank shaft being oriented longitudinally (parallel to the machine). In this case, must determine the reduced scheme framework, driven by the points of application of force and the centers of gravity line, specific to sections of the frame.

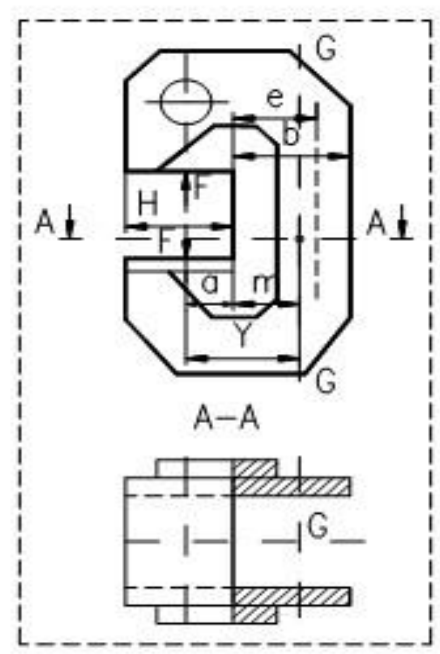

Figure 1. Reduced frame scheme

The reduced frame scheme in Figure 1 shows that in a certain section A-A the bed is subject to a bending moment, given by:

$$
M_{i}=F_{N A-A} \cdot Y
$$

where: $\mathrm{F}_{\mathrm{N}} \mathrm{A}-\mathrm{A}$ is the nominal deformation strength, corresponding to calculation section, $\mathrm{Y}$ - distance from the axis of force to the center of gravity calculation section.

Because along the beam represented by frame the bending moment remains constant, cross-sectional area considered is to be required for interior tensile and compressive on the outside.

Resistance modules for the two parts of the section will be considered:

$$
\begin{aligned}
& W_{t}=\frac{I_{z}}{m}\left[m^{3}\right]-\text { traction } \\
& W_{c}=\frac{I_{z}}{b-m}\left[m^{3}\right]-\text { compression }
\end{aligned}
$$

And the corresponding bending stresses:

$$
\begin{aligned}
\sigma_{i t} & =\frac{M_{i}}{W_{t}} N / m^{2}-\operatorname{int}(\text { traction }) \\
\sigma_{i c} & =\frac{M_{i}}{W_{c}} N / m^{2}-\operatorname{ext}(\text { compression })
\end{aligned}
$$

By overlapping with constant stress given by:

$$
\sigma_{t}=\frac{F_{N A-A}}{A_{A-A}} \quad N / m^{2}
$$

Maximum tensions will arise to external fibers of considered section:

$$
\sigma_{t \text { max }}=\sigma_{i t}+\sigma_{t} N / m^{2} \quad \sigma_{c \max }=\sigma_{i c}-\sigma_{t} N / m^{2}
$$

This calculation is presented through a numerical example, as stated by Iancu [7] represented by a cranktype press frame, type PMCR - 63 (Figure 2), mechanical press with half frame type (open) tilt, adjustable stroke and nominal force of $630 \mathrm{kN}$, crank shaft oriented longitudinally.

The classic calculation is only for maximum force, on its direction. This calculation is extended, as specified by Iancu in [8], by considering all cross sections of the frame, from $15^{\circ}$ to $15^{\circ}$, which allows estimation of tensions after several directions, providing information on both the maximum values and the distribution of these tensions, making sizing more accurate.

It also mentioned that for the calculation is made the assumption that the tensile and compressive efforts and deformations will be perpendicular to the direction A - A up to $G-G$, the calculating sections. Scheme for calculating the bed is shown in Figure 3. The frame is made of sheet plates from OL $44.2 \mathrm{k}$ in welded construction. According to the literature, wall thickness is between 8 and $60 \mathrm{~mm}$. Depending on similar machine tools made worldwide and those clauses in terms of characteristics, have settled the original dimensions from structural and functional conditions, followed by subsequent calculations, to finally check these dimensions.

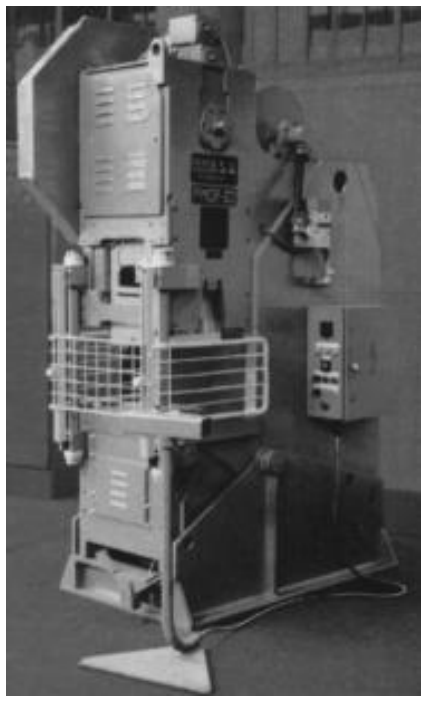

Figure 2. PMCR 63 press

It also states that, due to the symmetry of the bearing pedestal (of course, at this stage are not considered various technological clippings) will be performed the calculation for half the considered sections (see figure 4).

Sectional area is considered:

$$
\mathrm{A}_{\mathrm{t}}=135+180=0.0315 \mathrm{~m}^{2}
$$

The position of the center of gravity of the section will be: 


$$
y_{G}=\frac{\sum A_{i} y_{i}}{A_{t}}=\frac{135 \cdot 30}{315}=0.1285 \mathrm{~m}^{2}
$$

Moment of inertia of the composite section is considered:

$$
\begin{gathered}
I_{z}=\frac{\sum b_{i} h_{i}^{3}}{12}+\sum A_{i} y_{i}^{2} \\
=\frac{121500+1458000}{12}+43014+29722=204361 \cdot 10^{-8} \mathrm{~m}^{4}
\end{gathered}
$$

Resistance modules are:

$$
\begin{gathered}
W_{z_{1}}=\frac{I_{z}}{Y_{c_{1}}}=\frac{204361}{32.15}=6354.4 \cdot 10^{-6} \mathrm{~m}^{3} \\
W_{z_{2}}=\frac{I_{z}}{Y_{c_{2}}}=\frac{204361}{57.85}=3532.6 \cdot 10^{-6} \mathrm{~m}^{3}
\end{gathered}
$$

For section A-A, which is perpendicular to the direction of the force of the press, will be considered for calculating the nominal power of the press, so:

$$
F_{d}=630000 \mathrm{~N}
$$
be:

Bending moment acting on the considered section will

$$
M_{i}=\frac{F_{d}}{2}(25+32.15)=\frac{1}{2} 63000 \cdot 57.15=180022.5 \mathrm{Nm}
$$

Tensile constant stress is:

$$
\sigma_{t \text { int }}=\frac{F_{d}}{2 A_{t}}=\frac{31500}{315}=10^{7} \mathrm{~N} / \mathrm{m}^{2}
$$

Tensile stress, i.e. compression stress, due to bending loads will have values:

$$
\begin{gathered}
\sigma_{t \text { int } \text { inc }}=\frac{M_{i}}{W_{z_{1}}}=\frac{1800225}{6356.4}=283 \cdot 10^{5} \mathrm{~N} / \mathrm{m}^{2} \\
\sigma_{\text {c ext }}=-\frac{M_{i}}{W_{z_{2}}}=-\frac{1800225}{3532.6}=509 \cdot 10^{5} \mathrm{~N} / \mathrm{m}^{2}
\end{gathered}
$$

Maximum stress to outer fiber of the considered section will be:

$$
\begin{gathered}
\sigma_{t \text { int }}=100+283=383 \cdot 10^{5} \mathrm{~N} / \mathrm{m}^{2} \\
\sigma_{\text {c ext }}=100-509=409 \cdot 10^{5} \mathrm{~N} / \mathrm{m}^{2}
\end{gathered}
$$

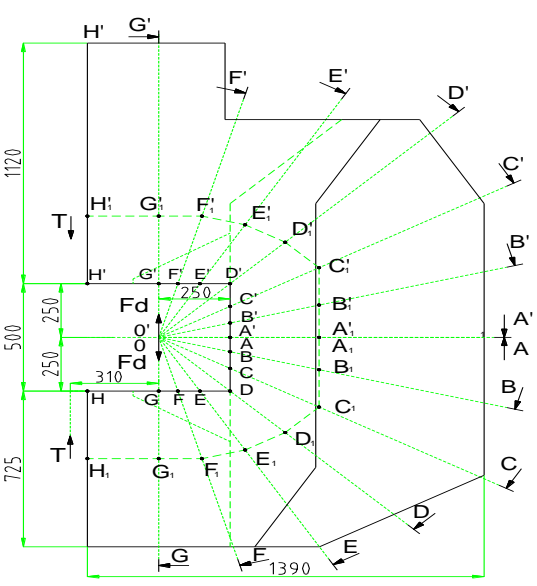

Figure 3. Scheme for calculating the bed

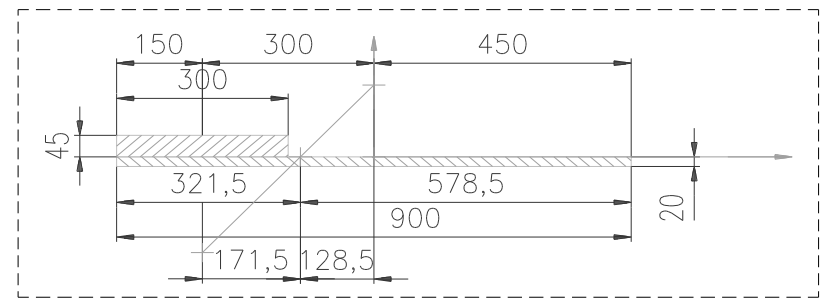

Figure 4. Section A-A

Following this model, calculation is performed in other sections of calculation considered B-B...G-G, determining for each: area and center of gravity of the section, moment of inertia and resistance modulus; force component acting on the section considered, the maximum stress for considering sections.

These elements are summarized in Table 1.

Table 1. Calculation elements for considering sections

\begin{tabular}{|c|c|c|c|c|c|}
\hline Section & $\begin{array}{c}\text { Area } \\
\mathrm{m}^{2}\end{array}$ & $\begin{array}{c}\text { Moment } \\
\text { of inertia } \\
\mathrm{m}^{4}\end{array}$ & $\begin{array}{c}\text { Force } \\
\mathrm{N}\end{array}$ & $\begin{array}{c}\sigma_{\text {int }} \\
\mathrm{N} / \mathrm{m}^{2}\end{array}$ & $\begin{array}{c}\sigma_{\text {ext }} \\
\mathrm{N} / \mathrm{m}^{2}\end{array}$ \\
\hline A-A & $315 \cdot 10^{-4}$ & $204361 \cdot 10^{-8}$ & 630000 & $3.83 \cdot 10^{7}$ & $4.09 \cdot 10^{7}$ \\
\hline B-B & $325.5 \cdot 10^{-8}$ & $221737.7 \cdot 10^{-8}$ & 608530 & $3.62 \cdot 10^{7}$ & $3.91 \cdot 10^{7}$ \\
\hline C-C & $360.7 \cdot 10^{-8}$ & $296109 \cdot 10^{-8}$ & 545590 & $2.95 \cdot 10^{7}$ & $3.22 \cdot 10^{7}$ \\
\hline D-D & $357.8 \cdot 10^{-8}$ & $163222 \cdot 10^{-8}$ & 445470 & $3.40 \cdot 10^{7}$ & $4.13 \cdot 10^{7}$ \\
\hline E-E & $431.5 \cdot 10^{-8}$ & $187022 \cdot 10^{-8}$ & 315000 & $2.16 \cdot 10^{7}$ & $2.23 \cdot 10^{7}$ \\
\hline F-F & $365.5 \cdot 10^{-8}$ & $185803 \cdot 10^{-8}$ & 163050 & $1.16 \cdot 10^{7}$ & $8.4 \cdot 10^{6}$ \\
\hline G-G & $326 \cdot 10^{-8}$ & $142904 \cdot 10^{-8}$ & - & - & - \\
\hline
\end{tabular}

As seen in Figure 5, which presents the distribution of these stress, the highest values are obtained in section A-A and section D-D, inclined at $45^{\circ}$, where, for a frame incorrectly sized may appear cracks in welding or even in basic material. Note that the absolute values of these efforts are quite small compared with the allowable material resistance, which shows that the frame is really oversized.

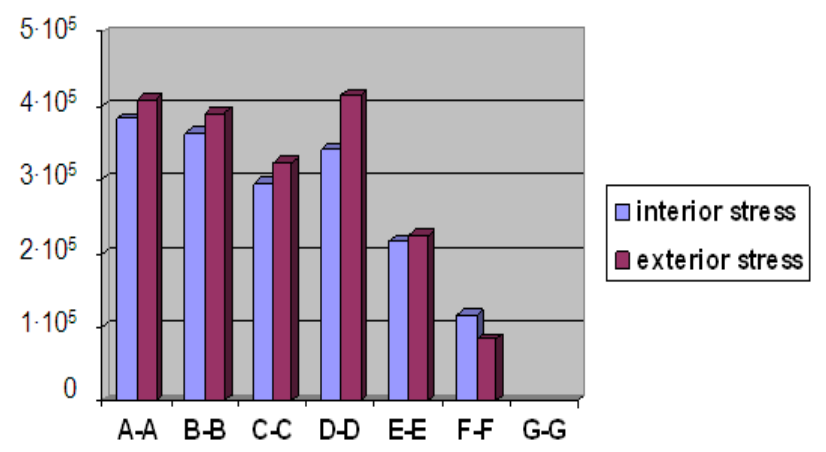

Figure 5. Stress distribution on frame sections

\section{Modeling Frame Strategy for FEA}

\subsection{General Elements}

For the discretization of any structure must be selected the most suitable finite elements, regarding the geometry, the loads, the desired precision and many other conditions.

In the majority of cases the structure geometry determines the finite element type to be used, as stated Imbert in [9]. It is recommended using a single type of 
finite element, but for complex structures may be used two or even more type of finite elements.

One-dimensional finite elements- are used when geometry, material properties, etc. may be described by a single space coordinate.

Bi-dimensional finite elements- are used when two space coordinates may describe geometry, material properties, etc.

Three-dimensional finite elements- are used when the structure is massive and the geometry, material properties, etc. may be described by three space coordinates. The base element is a tetrahedron, but may be used other shapes, like cuboids, prism, hexahedron.

At the same time the size of the elements is very important in order to achieve correct result and the desired precision. Regarding this aspect a compromise must be made between the size and the number of elements because increasing the number of elements leads to the growth of the problem, and increase the solving time.

If the analyzed structure has no geometry discontinuities, material properties and loads, can be divided in finite elements approx. equals, and the node distances will be uniform. The number of elements is connected with the desired precision, but it is a certain number of elements for that the relation precision-solving time is optimized, as stated by Rao in [10].

\subsection{Discretization Variants}

As Neumann and Hahn stated in [11], the frames of machines are generally complex structures, threedimensional, which requires a detailed analysis of variants for modeling and discretization. Theoretically can be used three possibilities of discretization, and thus obtaining three model variants:

- beam type elements, which have the advantage of easy modeling, a reduced solving time, but cannot accurate modeling concentrators zones;

- plate type elements which have the advantage of a detailed examination of local phenomena, but having a bigger solving time;

- solid type elements (three-dimensional), which models very exactly the whole structure, but having a large saving time.

It's also obvious that it can be combined various types of elements, when necessary.

By analyzing the geometry of the structure it comes to conclusion that can be discretized in majority with plate type finite elements. How the majority of bed elements is welded plates, it's clear that plates can model structure. The modeling is done on middle plane, regarding the thickness of plates. The bedplates have been discretized by SHELL elements with 3 nodes, the thickness of a plate being constant. For the reason of real convey of forces, the cantilevers and the bosses from the upper side have been discretized by SOLID elements.

The version of "COSMOS/M" software [12] used for solving, permit using three important classes of finite elements:

- One-dimensional (BEAM class);

- Bi-dimensional (PLANE2D class);

- Three-dimensional (SOLID class).

So the "COSMOS/M" software permits any variant of structure discretization, in order to achieve a model very real and to obtain result accuracy, especially when analyzing complex structures like a press bed.

\subsection{Modeling and Processing the Bed Model}

The solving time is main motivation in choosing a discretization variant and complying software. The appearance of a new solving technique (FFE - Fast Finite Element) developed by Structural Research \& Analysis Corporation was decisive in using COSMOS/M [13].

For solving a problem of structural analysis and optimization of a complex structure like a mechanical press bed must be followed certain phases:

a- completing geometric model; b- establishing the analysis type; c- defining the finite element type; ddefining the mesh; e- defining material characteristics; fdefining geometric characteristics.

a) Completing geometric model

First it must be realized a geometric model most accurate of the bed, using a dedicated CAD software, or even the geometric modeler of COSMOS/M. This modeler is quite cumbersome, so was chosen dedicated CAD software (it's recommended a soft that can perform parametric modeling and work integrated with FEA software). Such a program is Pro/Engineer [14], produced by American corporation Parametric Technology Corp. The problems and phases of modeling are not detailed here.

\section{b) Establishing the analysis type}

The load for such a structure is complex. Practically it is a dynamic load and the natural frequencies are very important. In this paper, will be presented the modeling and only the static analysis of the structure, made mostly for validating the geometric model.

\section{c) Defining finite element type}

After completing the geometric model, presented in Figure 6, for subsequent FEA, it must be done the meshing. It has been mentioned that the discretization can be done using plate elements (SHELL 3), or solid elements (TETRA 4). Since majority of the structure is realized of welded plates of different thickness, between $10-80 \mathrm{~mm}$, it will be used shell type elements for the whole structure, and for the cantilevers and the bosses, tetrahedron elements.

\section{d) Defining the mesh}

Using this type of finite elements it has been done the discretization of the structure, obtaining the mesh presented in Figure 7. The mesh was done directly in Pro/Engineer, because importing geometry in COSMOS/M and then creating the mesh in this software have revealed a series of inconsistencies as a result of a different precision of coordinates in the two programs. In addition Pro/Engineer has special facilities of refining the initial mesh.

\section{e) Defining material characteristics}

The refined mesh presented in Figure 7 has been imported in COSMOS/M, in this stage the compatibility being complete. For defining material measurement it has been used the SI system material library of software, existing the possibility of defining every property at row, measurement units according to the SI system material library of software, existing the possibility of defining every property at row, measurement units according to the SI system. 
The bed is made of OL $44.2 \mathrm{k}$, and the table is made of OL 52.2k, STAS 500/2-80. The material chosen from a library is STEEL (plain steel), which has the usual characteristics of this material.

f) Defining geometric characteristics

The geometric characteristics refer to this type of structure the thickness of every plate. When importing the mesh in COSMOS/M for FEA have been defined finite element groups, and also the thickness and FE type adjoin to every real constant (the initial thickness of every plate of the bed).

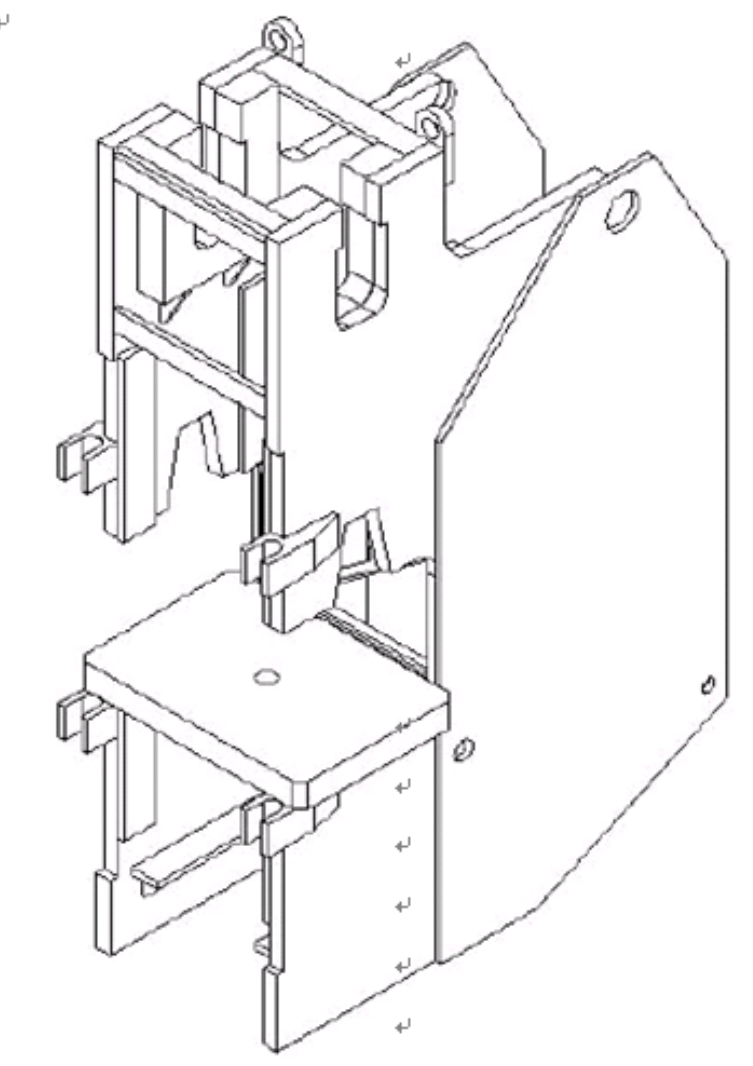

Figure 6. Geometric model of the press bed

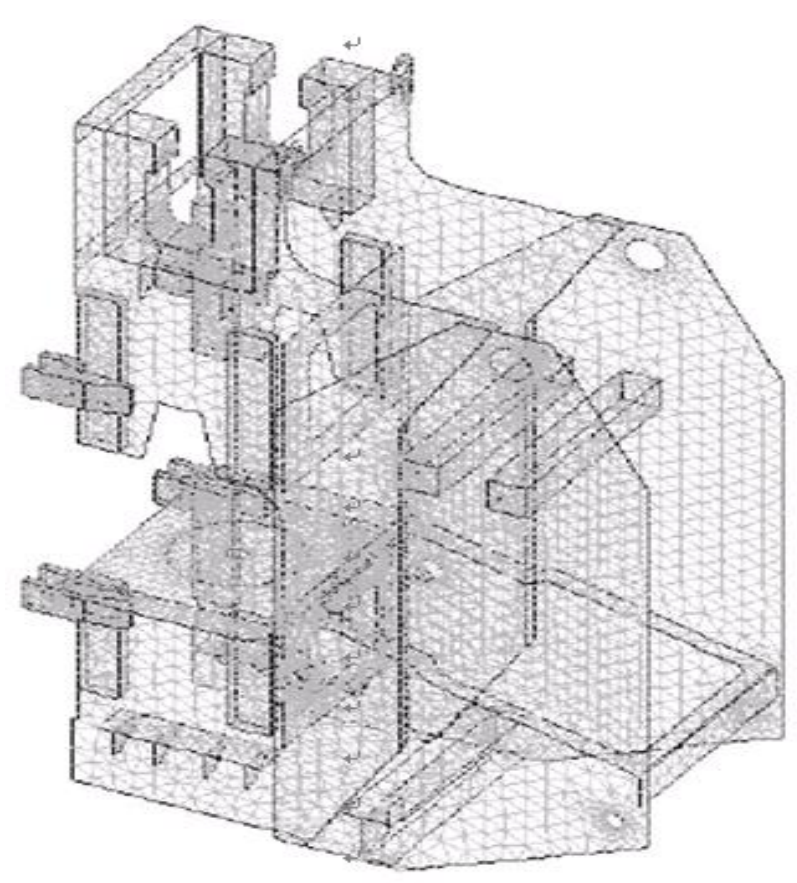

Figure 7. Refined mesh

\section{Static Analysis of PMCR-63 Mechanical Press Frame}

The model of the complex structure analyzed, completed and prepared as shown before, is now ready for finite element analysis. For FEA analysis, either static or dynamic, in COSMOS/M must be followed the phases: defining the mesh, defining the environment bonds, defining the loads, performing analysis and result interpretation.

\subsection{Defining the Mesh}

The mode of obtaining the mesh was presented before. The mesh has 10307 nodes, 25734 finite elements and 103590 degrees of freedom (DOF), element type SHELL 3 for discretization of all bed plates and type TETRA 4 for discretization of cantilevers and the bosses (Figure 8).

\subsection{Defining the Environment Bonds}

The bed structure may be studied in half, regarding the symmetry in plane YOZ. This symmetry regards the geometry, the loads and the environments bonds. However, for more accurate evaluation of the model was chosen the modeling of the whole structure. The environment bonds apply to nodes being in the zone of the bed resting on the foundation. In this zone are blocked all DOF (3 translations and 3 rotation). In Figure 9 are presented the environment bonds.
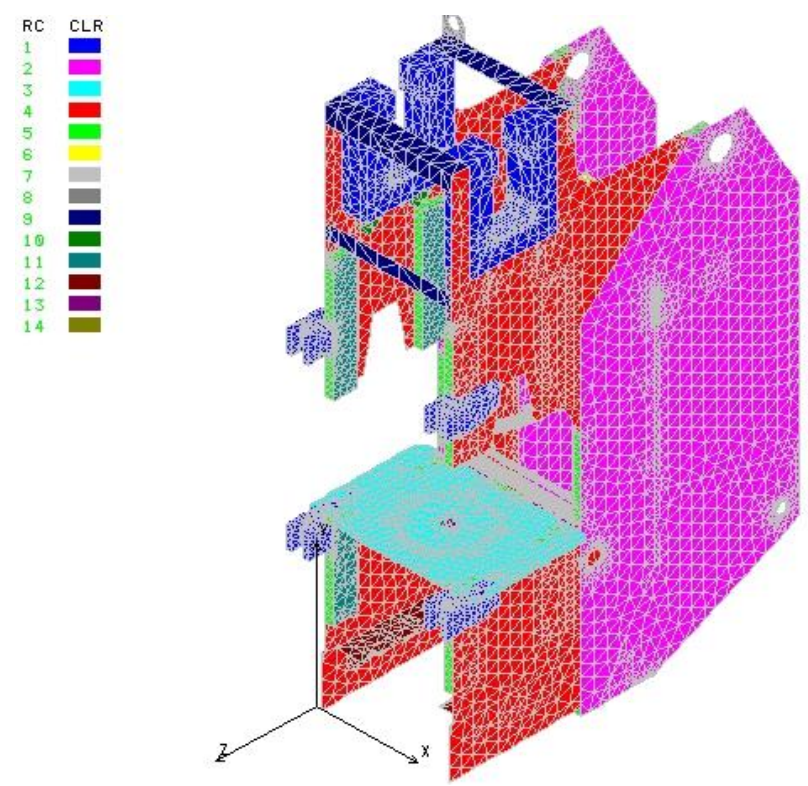

Figure 8. The discretized structure

\subsection{Defining the Loads}

Defining the loads of analyzed structure can be approached in many points of view:

- defining real loads (shock type, on short time, with hard to estimate damping), in this case is needed a detailed dynamic analysis;

- defining static loads, like a cutoff impairment of loads to static domain, when this is real enough.

The forces developped for on working are generated by rod-crank mechanism. Their effect is transmitted by 
superior bosses and by the bed table in the whole structure. Therefore, on the bed action: $\mathrm{tf}$

- action forces on bed table, with maximum value of 63

- reaction forces on the upper bosses, same value, but contrasted direction.
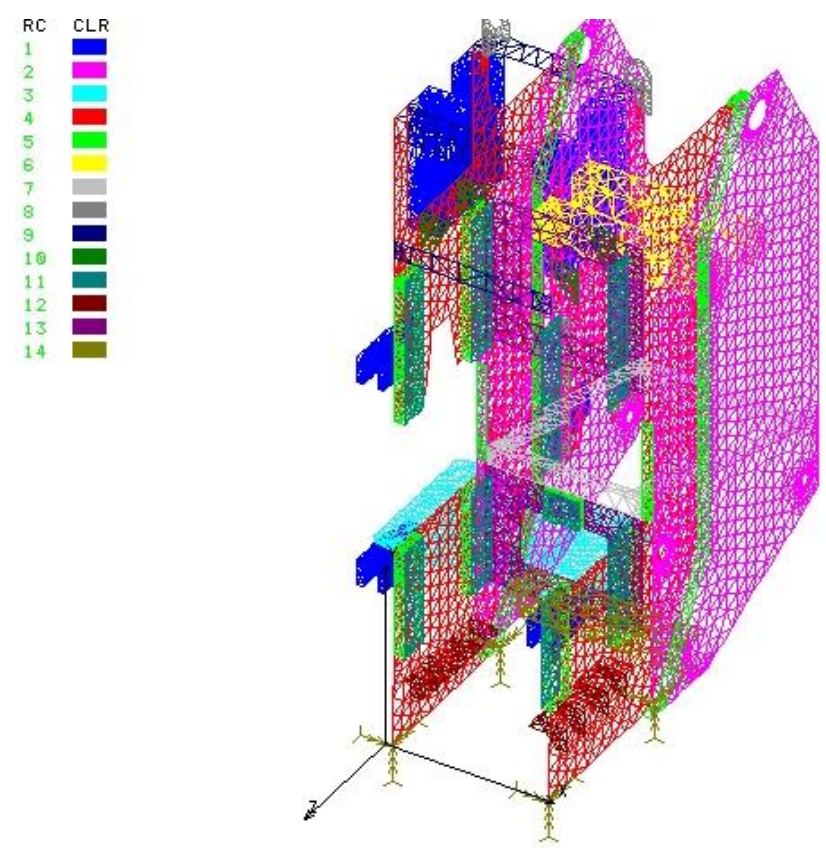

Figure 9. The environment bonds

Since the action of these forces doesn't concentrate, the forces on upper bosses were considered like a uniform distributed pressure on bosses' width, having the value:

$$
\mathrm{p}_{1}=630000 /(4 \times 25 \times 100)=63 \cdot 10^{6} \mathrm{~N} / \mathrm{m}^{2}
$$

And the force on bed table like a distributed pressure on circular surface of $300 \mathrm{~mm}$ diameter:

$$
\mathrm{p}_{2}=630000 \times 4 / \pi(3002-502)=9.17 \cdot 10^{6} \mathrm{~N} / \mathrm{m}^{2}
$$

In Figure 10 and Figure 11 are shown these pressures. To these loads is added the weight of the structure, considered by an automated option in the software.

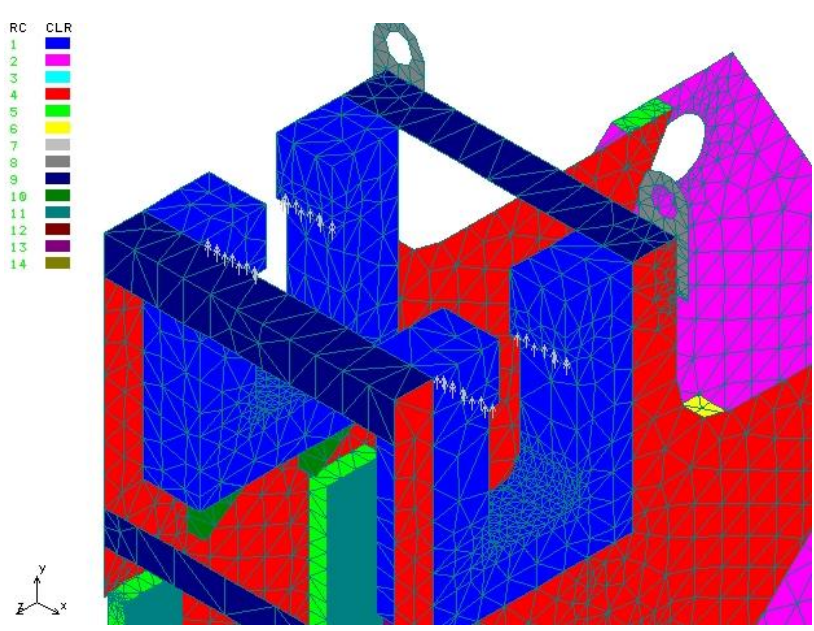

Figure 10. Pressure on bosses

\subsection{Performing Analysis and Result Interpretation}

The model prepared for analysis as shown, was studied with COSMOS/M, with solving option FFE (Fast Finite Element). The results show both displacement and stress, concerning maximum values and distribution. In Figure 12 is presented the stress distribution, by Von Misses theory.

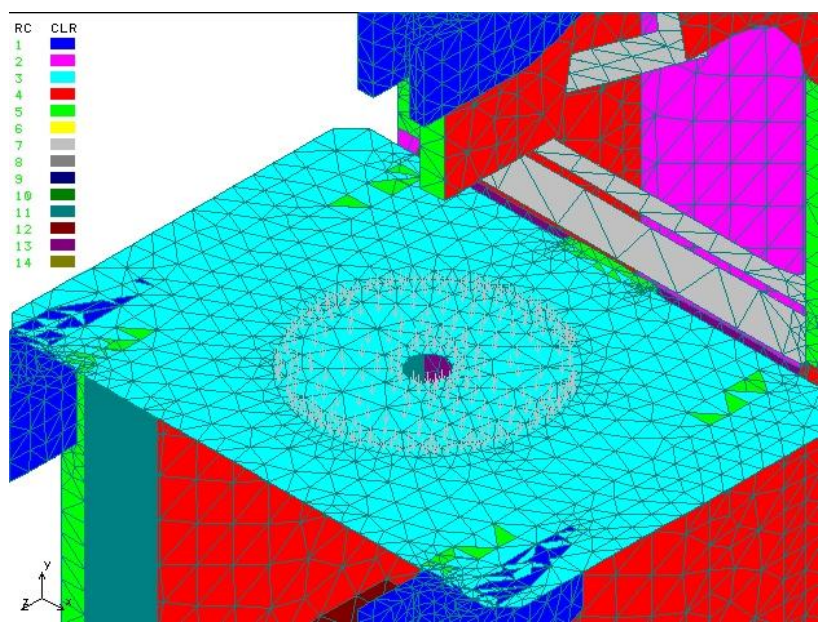

Figure 11. Pressure on bed table

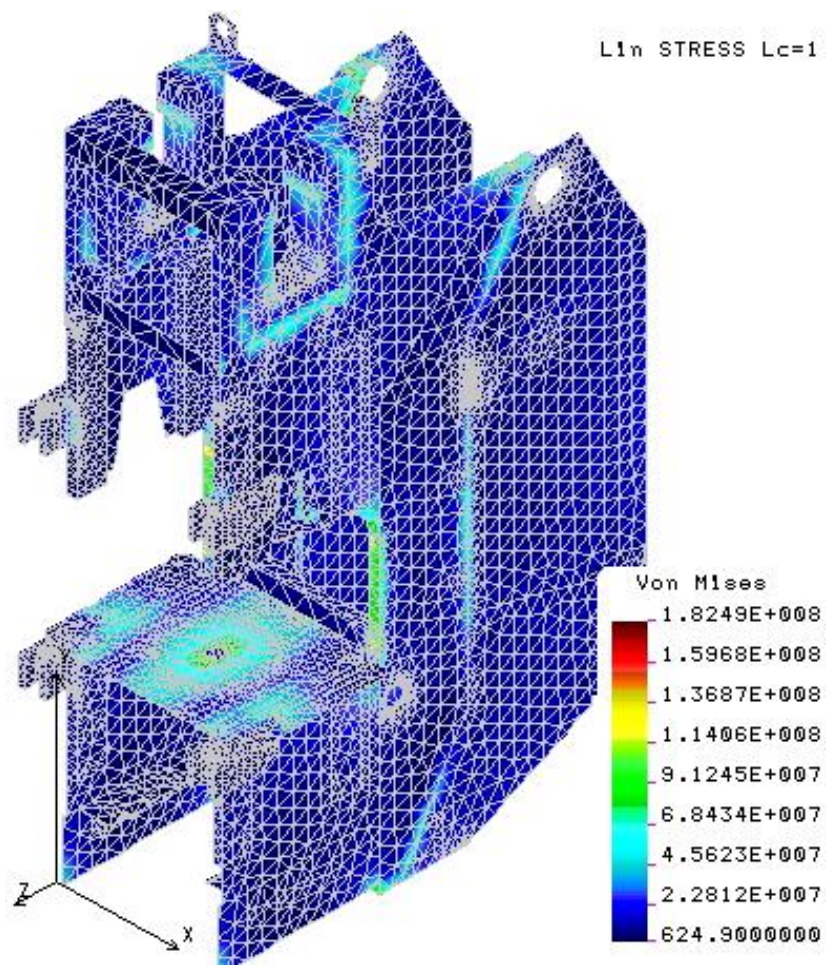

Figure 12. Von Misses stress distribution, $\sigma_{\text {Von }}, N / \mathrm{m}^{2}$

The admissible strengths considered are: bending strength $2 \cdot \mathrm{E}+08 \mathrm{~N} / \mathrm{m}^{2}$ and traction-compression strength $1.8 \cdot \mathrm{E}+08 \mathrm{~N} / \mathrm{m}^{2}$.

It can be noticed that stress values are generally low compared with traction-compression strength of bed material, $\sigma_{\mathrm{Von}}=1.8 \mathrm{E}+08 \mathrm{~N} / \mathrm{m}^{2}$, higher values being recorded only locally, in the bed table zone. The maximum stress is $1.82 \cdot \mathrm{E}+08 \mathrm{~N} / \mathrm{m}^{2}$, and because the structure is stressed on traction-compression compound with bending, the admissible strength considered is

$\sigma \mathrm{Von}_{\max }=2 \cdot \mathrm{E}+08 \mathrm{~N} / \mathrm{m}^{2}$, so the stress is below the admissible strength. 


\section{Conclusions}

This calculation presents a novelty compared with classical calculus because are considered different sections of the frame, from $15^{\circ}$ to $15^{\circ}$, which allows estimation of stresses after several directions, providing more information on both maximum values and the distribution stresses.

For a more accurate and complete stress values and their distribution is clearly required a more complex calculation, which allows eventually a dimensional optimization, considering real dynamic load, such as FEM, as stated by Neumann in [15].

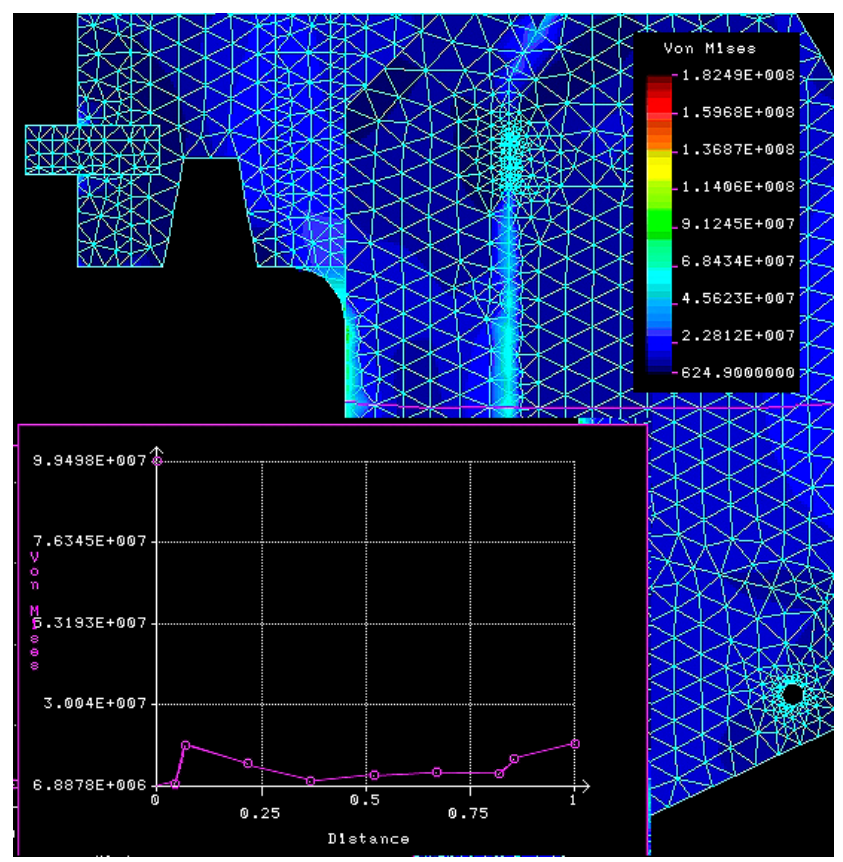

Figure 13. Von Misses stress corresponding to section A-A, $\sigma_{\text {Von }}, \mathrm{N} / \mathrm{m}^{2}$

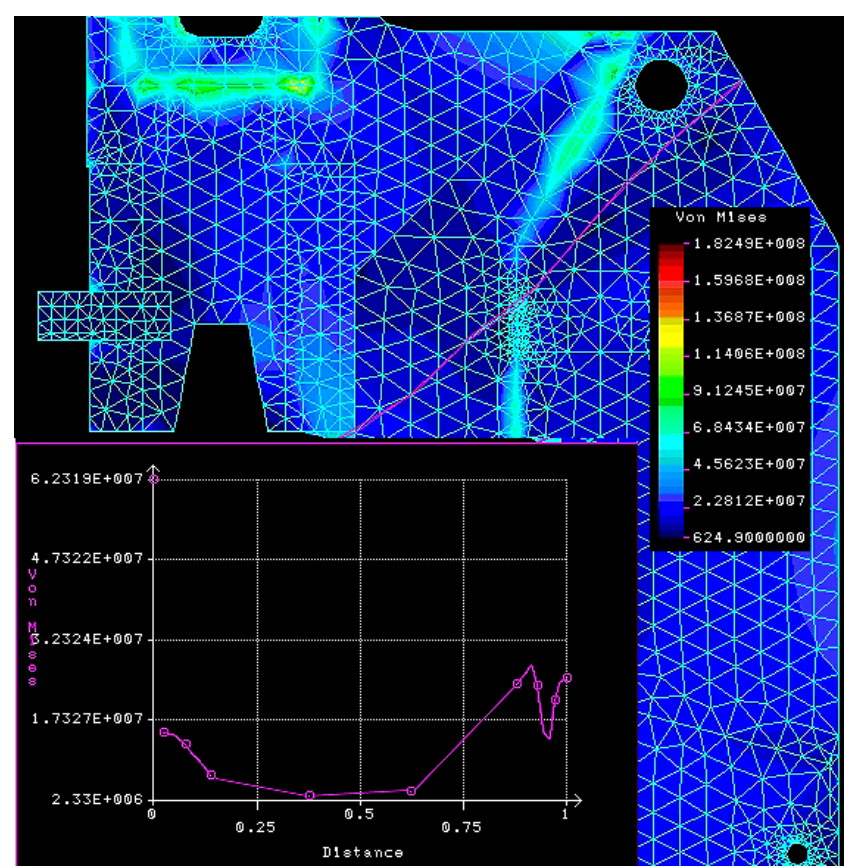

Figure 14. Von Misses stress corresponding to section D-D, $\sigma_{\text {Von }}, \mathrm{N} / \mathrm{m}^{2}$

So in the second part of the paper are presented the stages needed for modeling complex structures, such as a mechanical press bed, shown by a numeric example and also the preparing of the model for subsequent FEA analysis.

It has to be mentioned that the specialty literature is relatively poor in offering complex stress calculus on models realized in majority using SHELL elements, for plates made structures.

Based on FEA application the results show a continuous distribution of displacements and stresses that validate the model, proving it correct. It can be noticed that stress values are generally low compared with traction-compression strength of bed material, higher values being recorded only locally.

The maximum stress is $1.82 \cdot \mathrm{E}+08 \mathrm{~N} / \mathrm{m} 2$, and because the structure is stressed on traction-compression compound with bending, the admissible strength considered is $\square$ Von $\max =2 \cdot \mathrm{E}+08 \mathrm{~N} / \mathrm{m} 2$, so the stress is really below the admissible strength.

In Figure 13 and Figure 14 are presented the stress values obtained by FEA in section A-A, respectively D-D. In Table 2 is presented the comparison between the values obtained by classical calculus and by FEA.

Table 2. Comparison between classical calculus and by FEA

\begin{tabular}{|c|c|c|c|c|c|}
\hline Section & $\begin{array}{c}\text { Area } \\
\mathrm{m}^{2}\end{array}$ & $\begin{array}{c}\text { Force } \\
\mathrm{N}\end{array}$ & $\begin{array}{c}\text { Classical } \\
\text { calculus } \\
\sigma_{\text {int }} \\
\mathrm{N} / \mathrm{m}^{2}\end{array}$ & $\begin{array}{c}\text { Classical } \\
\text { calculus } \\
\sigma_{\text {ext }} \\
\mathrm{N} / \mathrm{m}^{2}\end{array}$ & $\begin{array}{c}\text { FEA } \\
\sigma_{\text {Von }} \\
\max \\
\mathrm{N} / \mathrm{m}^{2}\end{array}$ \\
\hline A-A & $315 \cdot 10^{-4}$ & 630000 & $3.83 \cdot 10^{7}$ & $4.09 \cdot 10^{7}$ & $<3 \cdot 10^{7}$ \\
\hline D-D & $357.8 \cdot 10^{-8}$ & 445470 & $3.40 \cdot 10^{7}$ & $4.13 \cdot 10^{7}$ & $<3.2 \cdot 10^{7}$ \\
\hline
\end{tabular}

It can be noticed that stress values obtained by classical calculus are higher than the values obtained by FEA, confirming the assumption that using only a calculation based on the simplified structure, leads to an oversized structure, the calculation method being usually used for verification.

Also, with this type of analysis it became possible knowing values in every point of the bed that interests, and preparing the way for the sizing optimization of such a complex structure, optimization considering dynamic load too.

\section{References}

[1] OSHA 1910.217, Mechanical power press requirements and platen presses, USA, 1991.

[2] I.C.P.M.U.A., Sibiu Subsidiary, Machine tools, typification rules, Romania, 2000.

[3] Schuler Inc., Metal forming handbook, Springer, Germany, 1998, 33-44.

[4] Smith, D.A., Mechanical press types and nomenclature, MI, USA, 2005, 1-27.

[5] Tabără, V., Catrina, D. and Ghana, V., Calculus, design and adjustment of presses, Technical Publishing House, Bucureşti, Romania, 1976, 71-80.

[6] Tschaetsch, H., Metal forming practice, Springer, Germany, 2005, 295-310.

[7] Iancu, C., Dimensional optimization of mechanical press, Ed MJM, Craiova, Romania, 2002, 30-50.

[8] Iancu, C., Contributions to dimensional optimization of mechanical press in dynamic regime, $\mathrm{Ph} . \mathrm{D}$. Thesis, University of Pitesti, Romania, 2002, 20-39, 160-190.

[9] Imbert, J.F., Analyse de structure par elements finis, Ecole Nationale Superieure de l'Aeronautique et de l'Espace, CepaduesEdition, Toulouse, France, 1991

[10] Rao, S.S., The finite element method in engineering, fifth edition, Elsevier, 2011, 53-63 
[11] Neumann, M., and Hahn, H., "Computer simulation and dynamic analysis of a mechanical press based on different engineer models", Mathematics and Computers in Simulation, Vol. 46, Issues 5-6, 1998, 559-574

[12] Cosmos/M -Finite Element Analysis System, User Guide, Structural Research \& Analysis Corp., Los Angeles, CA, USA, 2002.
[13] Cosmos/M -Finite Element Analysis System, Basic FEA System, Structural Research \& Analysis Corp., Los Angeles, CA, USA, 2002.

[14] Pro/Engineer -User guide, Parametric Technology Corporation, Waltham, MA, USA, 2001

[15] Neumann, M., Dynamic analysis of mechanical presses, RTS Scientific rapport, Kassel University, Germany, 1994. 